\title{
Health care management resources
}

\section{Web sites for the national debate}

A ccording to the Centers for Medicare and Medicaid Services (CMS), the United States is projected to spend more than $\$ 2.5$ trillion on health care in 2009 , or $\$ 8,160$ per U.S. resident. Health spending in 2009 is projected to account for 17.6 percent of gross domestic product. ${ }^{1}$

Despite high spending, nearly 46 million Americans are still uninsured. While policy and law makers agree that health care reform is needed, they disagree on how to contain the escalating health care costs and offer universal coverage. Some have suggested imposing price controls and strict budgets on health care spending, and others support free market competition.

To understand competing proposals on management and delivery of health care services, one needs to be familiar with factors and policies influencing the health care systems in the United States and other countries.

This guide highlights free Web sites with data and information on issues relevant to the national health care debate, including health care cost, coverage, expenditure, access, delivery, utilization, disparities in quality, and outcomes.

\section{Models}

Listed below are Web sites that provide an overview of various health care models.

- Theoretical Models for Delivering Health Care. This primer by the American Medical Student Association explains basic concepts related to various health care payment models, such as single payer systems, multi-payer systems, tax credits, medical savings accounts, and managed competition and also provides pros and cons for each. Access: http://www.amsa.org/uhc/ theories.cfm.

- What Is Socialized Medicine?: A Taxonomy of Health Care Systems. Uwe E. Reinhardt, an economics professor at Princeton University explains in layman's terms the differences between socialized medicine and social health insurance. Access: http:// tiny.cc/FLFZ0.

\section{Trends}

- America's Health Rankings. Produced collaboratively by the United Health Foundation, this annual ranking analyzes national health on a state-by-state basis. It focuses on 22 different health measures to determine national health benchmarks and produces an annual ranking of the healthiest and least healthy states. Access: http://www. americashealthrankings.org/.

- Employer Health Benefits Annual Survey. This annual survey has been conducted since 1999 and tracks trends in employer health insurance coverage, including changes in premiums, employee contributions, cost-sharing provisions, and other relevant information. Findings are based on a nationally representative survey of public and private employers, including those who respond to the full survey and those who indicate only whether they provide

Shikha Sharma is the business, economics, and legal studies librarian at the University of Connecticut, e-mail: shikha. sharma@uconn.edu

(c) 2009 Shikha Sharma 
health coverage. Access: http://www.kff.org /insurance/ehbs-archives.cfm.

- Trends and Indicators in the Changing Health Care Marketplace. This report prepared by the Health Care Marketplace Project, a Kaiser Foundation initiative, highlights trends in the health care market, particularly as they affect vulnerable groups like the poor and the elderly. It also analyzes policy proposals that involve the private health care system. Access: http://www.kff. org/insurance/7031/index.cfm.

- Trends in Health Care Costs and Spending. A fact sheet from the Kaiser Foundation on health care costs with key statistics on growth, level, and impact of rising U.S. health care costs. It covers spending on various medical services, sources of health spending, employer-sponsored health coverage, and the impact on businesses and people. Access: http://www.kff.org /insurance/7692.cfm.

\section{Health care providers: Directories and rankings}

- America's Best Hospitals. Published in U.S. News and World Report, this annual list ranks hospitals in 16 specialties including cancer, gynecology, heart and heart surgery, ophthalmology, neurology and neurosurgery, psychiatry, and respiratory disorders. Access: http://health.usnews.com /sections/health/best-hospitals/index.html.

- Hospital Compare. Developed jointly by the Centers for Medicare and Medicaid Services and the Department of Health and Human Services, this tool allows one to find and compare hospitals. It provides information on how well hospitals care for patients with certain medical conditions or surgical procedures based on the results from a survey of patients about the quality of care they received during a recent hospital stay. Access: http://www.hospitalcompare.hhs.gov/.

\section{Cost, coverage, expenditure, and quality}

- Agency for Healthcare Research and Quality (AHRQ). The mission of AHRQ is to improve the quality, safety, efficiency, and effectiveness of health care for all Americans. The AHRQ Web site provides information on a variety of health topics focusing on specific populations and types of health care services. Access: http://www.ahrq.gov/.

Of particular significance are the following surveys available on the AHRQ Web site:

- The Healthcare Cost and Utilization Project (HCUP). The HCUP Project is a series of databases that provide patient-level health care data produced through a federal, state, and industry partnership. These databases enable researchers to identify, track, and analyze trends in health care utilization, access, charges, quality, and outcomes of treatments at the national, state, and local market levels. While the raw data from the HCUP databases are available for purchase, the Web site provides some free data query tools (HCUPnet, AHRQ Quality Indicators) that can be used to search and access statistics from select HCUP databases. Access: http://www.hcup-us.ahrq. gov/databases.jsp.

- The Medical Expenditure Panel Survey (MEPS). MEPS is a set of national surveys administered to families and individuals, their medical providers, and employers. MEPS collects data on the specific health services that Americans use, how frequently they use them, the cost of these services and how they are paid for, as well as data on the cost, scope, and breadth of health insurance held by and available to U.S. workers. Access: http://www. ahrq.gov/data/mepsix.htm.

- National Healthcare Quality and Disparities Reports. The National Healthcare Quality Report tracks the health care system through quality measures, such as the percentage of heart attack patients who received recommended care when they reached the hospital or the percentage of children who received recommended vaccinations. The National Healthcare Disparities Report summarizes health care quality and access among various racial, ethnic, and income groups and other priority populations, such as children and older adults. Reports from previous years 
going back to 2003 are also available. Access: http://www.ahrq.gov/qual/qrdr08.htm.

- Center for Medicare and Medicaid Services (CMS). CMS provides direction and technical guidance to plan, develop, manage, and evaluate health care financing programs and policies. The CMS Web site provides access to reports, newsletters, data and publications relating to health care costs, coverage, expenditure, and plans in the United States. Access: http://www.cms.hhs.gov/.

- The National Committee for Quality Assurance (NCQA). NCQA is a private, nonprofit organization that studies and reports on quality of health care. The site offers free access to report cards on NCQAaccredited health plans and an annual report on the "State of Health Care Quality," which tracks performance trends over time. It also makes recommendations for future quality improvement. Access: http://www.ncqa.org/.

- Quality Check. Administered by the Joint Commission on Accreditation of Healthcare Organizations, this search engine can be used to identify both commission-accredited and non-accredited health care organizations. For commissionaccredited institutions, a summarized quality report indicating the organization's name, accredited programs, address, sites, and services is available. Access: http://www.qualitycheck.org/Consumer /SearchQCR.aspx.

- Statehealthfacts.org. This project of the Henry J. Kaiser Family Foundation provides free and current health data on all 50 states. One can consult individual state profiles and also compare and download data on a variety of topics, including health status, health coverage and uninsured, Medicaid and CHIP, health costs and budget, managed care and health insurance, providers and service use, minority health, women's health, and HIV/AIDS. Access: http://www. statehealthfacts.org/.

\section{statehealthfacts.org}

\section{Health care utilization}

- National Center for Health Statistics (NCHS). NCHS is a division of the Center for Disease Control and is one of the primary collectors of health and vital statistics. NCHS administers many surveys to document the health status of various populations and to monitor trends in health care delivery. Access: http://www.cdc.gov/nchs/.

Listed below are some of the surveys conducted by the Center NCHS.

- National Health Care Survey (NHCS). NHCS addresses issues, such as the factors that influence the use of health care resources; the quality of health care, including safety; and disparities in health care services among various population subgroups in the United States. Surveys are conducted at various settings where the health care is provided such as physician's office, emergency and out-patient hospital departments, inpatient hospital care, ambulatory surgical facilities, nursing homes, and hospice care providers. Access: http://www. cdc.gov/nchs/nhcs.htm.

- National Vital Statistics System. These surveys are the official source for U.S. vital statistics: births, deaths, marriages, divorces, and fetal deaths. Access: http://www.cdc.gov /nchs/nvss.htm.

For a complete listing of NCHS surveys. Access: http://www.cdc.gov/nchs/surveys. htm.

- Dartmouth Atlas of Healthcare. The Atlas provides comprehensive information and analysis on how medical resources are distributed and used in the United States. It provides comparative data on hospital expenditures, capacity, and per capita expenditures; Medicare reimbursements for inpatient, outpatient, and home health care; physician work force active in patient care; rates of diagnostic and surgical procedures; and hospital capacity and Medicare hospitalizations. The site offers interactive tools that can be used to create customized reports, comparative analysis, and chart- 
ing. Access: http://www.dartmouthatlas. org/index.shtm.

- Survey of Health Care Consumers. This annual survey conducted by the Deloitte Center for Health Solutions, is Deloitte's second annual study of health care consumers' attitudes, behaviors, and unmet needs. It covers six broad topics: wellness and healthy living, including self-care and health management; information sources helpful in consumer decision making; traditional health services provided by medical professionals, hospitals, and retail clinics, as well as prescription medications and medical devices; alternative health services sometimes described as complementary medicine; insurance coverage and other financial considerations; and opinions about health care reform. Access: www.deloitte. com/us/2009consumersurvey.

\section{Comparative foreign health care systems}

This section focuses on the structure of health care systems in other countries, covering topics such as financing, reimbursement, delivery systems, and adoption of new technologies.

- European Observatory on Health Systems and Policies. The Web site features profiles of health care systems in various European countries. It also links to healthrelated Web sites in each country, including ministries of health, national public health institutes, and centers for health policy, public health, and health economics. Access: http:// www.euro.who.int/observatory/ctryinfo /ctryinfo.

- The Grass is Not Always Greener: A Look at National Health Care Systems Around the World. This well-researched paper from the Cato Institute explores different types of national health care systems and then focuses on specific countries, including France, Italy, Spain, Japan, Norway, Portugal, Greece, Netherlands, Great Britain, Switzerland, Germany, and Canada. Access: http://www.cato.org/pubs /pas/pa-613.pdf.
- Health Care System Profiles. The Commonwealth Fund's International Program conducts surveys in partnership with other entities to study industrialized countries' health care systems; how they organize, finance, and deliver health services. These surveys also highlight quality, efficiency, and cost-controlling policy initiatives and reforms. Full-text profiles of various countries are available for download. Access: http:// www.commonwealthfund.org/Content /Resources/2008/Mar/Health-Care-System -Profiles.aspx.

- Health in the Americas. This site profiles health care systems of Pan American Health Organization's member countries. The profile includes health situation trends, health problems by population group, national health plans and policies, health services offered, and organization of the health sector. Access: http://www.paho.org/english /country.htm.

- WHO Statistical Information System (WHOSIS). This interactive database provides core health statistics for the World Health Organization's 193 member states. It covers more than 100 indicators, which can be accessed by way of a quick search, by major categories, and through user-defined tables. The data can be further filtered, tabulated, charted, and downloaded. Major topics include vital statistics, health service coverage, health systems, inequities in health care, and risk factors. Access: http://www. who.int/whosis/en/.

\section{Policy and reform}

The Web sites listed below study and analyze health care policy issues, including health care system performance, cost and financing, quality and disparities, and implications of budget and tax policies and politics.

- The Congressional Budget Office (CBO). CBO's Health unit prepares reports and presentations to help estimate the budgetary impact of federal health programs. It conducts studies to support health policy discussions on Medicare, Medicaid, pharmaceuticals, public health, and private health 
market. Many of these documents, including cost estimates of recent health care reform proposals, are available on CBO's Web site. Access: http://www.cbo.gov/publications /collections/health.cfm.

\section{(2) Congressional Budget Office}

Home - Publications - Cost Estimates - About CBO - Press - Employment - $\mathrm{C}$

- Health Hippo. A collection of policy and regulatory resources related to health care. Don't forget to tickle the hippo to find out what is new. Access: http://hippo. findlaw.com.

- The Henry J. Kaiser Family Foundation. The Kaiser Family Foundation is a nonprofit, private THE HENRY ]. KAISER FAMILY $\overline{\text { FOUNDATION }}$ foundation that focuses on the major health care issues facing the United States as well as on the U.S. role in global health policy. Its Web site offers a wealth of information on health care issues, including research and analysis, fact sheets, data, reports, survey results, and side-by-side comparison of major health reform proposals. Access: http:// healthreform.kff.org/.

- The Medicare Payment Advisory Commission (MedPAC). MedPAC is an independent Congressional agency that advises Congress on issues affecting the Medicare program. The MedPAC Web site provides access to many documents, including reports, statistics, and congressional testimony on topics such as physicians and ambulatory care, private plans, health care spending, hospitals, beneficiaries, quality, outpatient therapy and more. Access: http:// www.medpac.gov/index.cfm.

- National Conference of State Legislators (NCSL). NCSL is a bipartisan organization that provides research support to legislators on critical state issues, including health. The NCSL Web site provides access to reports, articles, and legislative summaries related to health policy topics such as access and reform, finance and cost containment, health information technology, insurance, long-term care, Medicaid, prescription drugs, primary care, public health and wellness, and workforce issues. Access: http://www.ncsl.org/IssuesResearch /Health/.

- National Health Policy Forum. An independent, nonpartisan organization based at Georgetown University, the National Health Policy Forum aims to educate congressional and federal agencies' staff on significant health issues. The forum's site provides access to numerous publications, including background papers, briefing books, basics, and glossaries on topics such as Medicare, Medicaid, health insurance and uninsured, Children's Health Insurance Program, pharmaceuticals, and public health. Access: http:// www.nhpf.org/.

- RAND: Health COMPARE. This Web site by Rand Corporation includes sections on the current state of the health care system, framework for classifying health policy proposals, analyzing policy options, and modeling estimates. The site also includes a "hot" legislation page with links to key documents released by the White House, Congress, and federal agencies. Access: http://www. randcompare.org/.

- Robert Wood Johnson Foundation. A not-for-profit foundation that primarily focuses on health care. Its Web site offers news, data, articles, research reports, and white papers on health policy issues, such as long-term care, health care coverage, reform, disparities, quality, and public health. Access: http://www.rwjf.org/.

\section{Note}

1. Centers for Medicare and Medicaid Services, Office of the Actuary, 2009. "National health expenditure projections 2008-2018, forecast summary and selected tables." Centers for Medicare and Medicaid Services Website, www.cms.hhs.gov /NationalHealthExpendData/downloads /proj2008.pdf (accessed: June 30, 2009). $\boldsymbol{n}$ 